\title{
CAPITAL DISCOVERY PLACE TE AHO A MAUI, WELLINGTON Paul Thompson*
}

\begin{abstract}
Interactive or "hands-on" science centres and children's museums are well established overseas but Capital Discovery Place Te Aho a Maui will be NZ's first. Naturally enough it will reflect our own cultural uniqueness as well as expanding on the work that has previously been done here and abroad in the field of informal (that is, not school based) education.
\end{abstract}

Exhibits and programmes within our institution will change; major exhibit areas will have a life of around five years as a cycle of one main exhibit theme changing annually is intended. This constant updating will work to attract return visitors but it also means that, as well as being able to react to current concerns, exhibits will always be able to provide the most recent information available. All exhibit themes, including scientific and technical subjects, will be covered in a way that will include social and cultural aspects.

The opening theme for the general 'Elementals' area will be earthquakes. The subject, while a potentially emotive and possibly distressing one, will be addressed so that earthquakes are seen as a natural occurrence that can be planned for.

Listed below are some of the initial thoughts on possibilities for the 'Quakes' show:

\section{ATTRACTOR OR ENGAGING EXPERIENCE.}

There will be an earthquake simulation, probably not to scientifically accurate standards, but some form of re-creation that will involve and excite the visitors. There is already such a simulation in the audio-visual display at The Stables Museum in Napier where the whole seating area shakes at appropriate times to an accompanying video. Whether such a system is used, or something more sophisticated is

\footnotetext{
* Development officer

Capital Discovery Place Te Aho a Maui, wellington
}

developed, is not yet certain. Mentioned has been the possibility of corridors that shake as visitors move along them approaching the exhibit area or even mini-quakes in different parts of the museum to stimulate the visitor to purposefully visit the 'Quakes' display for further information.

Myths and Legends.

By going through a dark tunnel (underground) visitors will encounter Ruaumoko the Maori personification of earthquakes. Stories from other cultures such as the Japanese idea that earthquakes are caused by a giant catfish who lives under the sea and who is held quiet by a large stone that it sometime manages to cast off would also feature in this area. With the Pacific ocean being encircled by an earthquake prone zone there will no doubt be lots of material from our fellow Pacific peoples to illustrate differing perceptions about earthquakes. This cross cultural theme then leads to:

Earthquake Measurement, Forecasting.

Historical ways of predicting earthquakes eg; the Chinese use of natural phenomena and animal behaviour (perhaps a tie-in with our live animals area) and a reconstruction of the ancient Japanese dragon mechanism for recording earthquakes. Current methods may well be demonstrated by children trying to creep up on a seismograph. Modern research, such as monitoring of earth sounds, may provide a starting point to discuss the future possibilities of forecasting. This area will cover how earthquakes are measured, scales, damages etc. With the "scientific" Iine established we move to causes:

\section{Plate Tectonics.}

current theories of moving plates; perhaps children can stand on the Indo-Australian plate and grind it into the Pacific plate to get an idea. Concepts of subduction could be experienced on the same large model. Displays on strata and physical forces of earthquakes such as bent railway lines. To cover ideas of tremors moving from an epicentre children may be able to "Dial an earthquake". This uses a large model of NZ 
which could be stood on. By selecting an historical earthquake, rods may rise from various points on the model demonstrating how the shock waves travel and the varying depth of earthquake centres, (plus the visitors have to move out of the way!) Physical evidence leads to:

\section{Historical Perspective.}

Eyewitness accounts from children who have been in major earthquakes. They could be done as recordings and introduce the theme of earthquakes as being survivable. Some work of this sort has already been done at Edgecumbe with pupils writing and publishing their reactions to the Bay of Plenty Earthquake. However we would need more "active" forms of presenting experiences than a written record. There could also be provision here for museum visitors to record their own experiences.

\section{Prevention/Current Technology.}

How buildings, bridges, tunnels are protected against earthquakes in NZ. Perhaps a trip to our basement to see our own features in this line or large working models to play with and demonstrate the standard methods. It is envisaged that there will be both computer and physical interactives in this area so that children can explore the different concepts that are used in engineering against earthquakes

\section{CHOOSE YOUR OWN EARTHQUAKE KIT.}

From a large heap each child chooses three/four items for their own earthquake kit. Civil Defence are suspicious of this idea and feel that the options would have to include the range of items that they recommend for such kits. (There could be an analysis procedure afterwards to check against the civil Defence list). As a development with a school class, they could then go into a simulated post.earthquake area with piles of brick, stone, wood etc, and have to make a shelter from this material.

\section{CIVIL DEFENCE HEADQUARTERS.}

In a simulation of Civil Defence $\mathrm{HQ}$, children act out the roles of civil defence co-ordinators responding to reports coming in from outlying sector stations and directing resources to what they feel are the most appropriate areas. As a complementary activity perhaps a role-play could be developed that the children can perform in their own schools (since schools are $C D$ sector headquarters). Possibilities could include board games. The children would then learn how the $C D$ processes work 'on the ground' as it were. This should lead to an awareness of the need for self-help and also for precautions that can be taken now such as fastening water cylinders etc. This will prepare the ground (excuse the pun) for:.......

\section{FIRST AID.}

Practical demonstrations and instructions on how to respond to any situation requiring first aid. Perhaps an appropriate place to discuss shock and post-disaster neurosis. Ties in with Health and Wellbeing which is another of our theme areas.

OUTSIDE THE MUSEUM.

By buying a guide from the resource centre children can make connections with the effect that earthquakes have had on the natural and urban environment. They can note earthquake related features such as faultines, motorway safety features, building design, Wellington landforms altered by earthquakes. The museum can also be a distribution point for DSIR "felt reports" which people fill out and send to the department whenever they feel an earthquake. At home they can help make up an earthquake survival kit and then send us a report of what it contains. We can then develop this into the kidex area ( an area in which children mount their own exhibitions, with a collection of what different people consider necessary. There may well be telling additions to the normal range of equipment such as cosmetics, cuddly toys, or bike repair kits.

As Capital Discovery place Te Aho a Maui wishes to integrate science, aesthetics and experience in an holistic approach, there may also be scope for the use of earthquakes as a starting point in the other theme areas of Music and Media.

\section{MUSIC.}

In the recording studio children can use prerecorded crashes, earthgroans etc. to sample and create their own Earthquake music. These can be put into Quakebox (a jukebox with these recordings plus a few conventional classics such as "Whole lot of shaking going on" and "Living on the faultine" or any other appropriate music.) This would probably be an activity for older children as we do not want to promote the idea that earthquakes are fun.

\section{MEDIA.}

The recent San Francisco Earthquake has provided us with a chance to expand the Quakes theme into other areas. We can compare the coverage an earthquake in $\mathrm{Nth}$ America or Japan gets compared to one in Central Turkey. Children can analyze what makes a disaster a disaster - why two hundred killed in a developed country get a week of headline lines while two thousand killed in the 3 rd world hardly rates a mention. How do we get our views of the wider world?

These are a few ideas that illustrate the range of possibilities that we are considering. There are no doubt other aspects and approaches that will become 
apparent as research continues. At a recent meeting with our staff, Bruce shephard, Structural Engineer with Works, mentioned the idea of a timeline of 3 seconds, 3 hours, 3 days etc. as an organising concept for an earthquake exhibition. This is a useful and valued suggestion. We wish to consult as widely as possible on all our activities and so would appreciate suggestions for exhibits, programmes and activities. Even reports of overseas public education programmes/exhibits based on earthscience themes or research material would be received with interest.

of course any enthusiasms anyone has on any subject, either within or beyond the cosmos. that they feel would be of particular interest or importance to children please contact us at Capital Discovery Place Te Aho a Maui, Box 11-513 wellington, Ph (04) 732614, Fax (04) 732685 